\title{
Optimism as a predictor of health-related quality of life in psoriatics
}

\author{
Joanna Miniszewska ${ }^{1}$, Jan Chodkiewicz' ${ }^{1}$ Alicja Ograczyk², Anna Zalewska-Janowska²
}

1 Institute of Psychology, University of Lodz, Poland

Head: Prof. Eleonora Bielawska-Batorowicz

2Department of Psychodermatology, Medical University of Lodz, Poland

Head: Prof. Anna Zalewska-Janowska MD, PhD

\begin{abstract}
Introduction: Psoriasis is a chronic and relapsing disease which significantly affects the quality of life and social functioning of the affected people. It is one of the so-called psychodermatological diseases, which means that there exists a psychological component in the image of the disease.

Aim: To examine the relationship between health-related quality of life (HRQoL) in psoriatics and selected demographic, medical and psychological (dispositional optimism) variables and to determine the predictors of HRQoL in the examined group.

Material and methods: The study consisted of 138 patients with the diagnosis of psoriasis vulgaris. Most respondents (125) had psoriasis on exposed parts of the body. Methods used: SKINDEX, Life Orientation Test, PASI.

Results: The gender does not differentiate patients in terms of HRQoL and optimism. Almost all of analyzed variables correlate with HRQoL and all examined variables explain the results variability for overall HRQoL but only optimism explains the highest percentage of the variability $(\beta=-0.35)$.

Conclusions: The study demonstrated a very interesting relationship - the stronger optimism the better quality of life in psoriatics. So, a generalized expectation of positive life events is related to better assessment of HRQOL.
\end{abstract}

Key words: quality of life, optimism, psychodermatology, psoriasis.

\section{Introduction}

Psoriasis is a common multifactorial disease, in which genetic background plays an important role. It runs a chronic and relapsing course. The disease is one of the so-called psychodermatological diseases, which means that there exists a psychological component in the image of the disease [1-4]. The impact of psychological factors in the pathogenesis of psoriasis has been long recognized and already in the 1950 s an established correlation between stress and psoriasis was postulated $[5,6]$. Also O'Leary et al. [7] reported a strong belief in stress attributes as a causal factor in $61 \%$ of the examined psoriatic patients, however they did not find any association between the perceived stress and more objective measures of psoriasis severity.

Psoriasis is most often accompanied by mood disorders and has higher associations with psychiatric illness than other dermatologic conditions [8]. The prevalence of depression is estimated to be approximately 57\% and 5\% of people treated for psoriasis attempt suicide [9-11].

As it is clear from several studies, psoriasis significantly affects the quality of life and social functioning of the affected people [9, 10, 12-14].

Health-related quality of life (HRQoL) reflects patients' evaluation of the impact of disease and treatment on their physical, psychological, and social functioning and wellbeing $[15,16]$. Some studies indicate that the adverse impact of psoriasis upon the quality of life can result in chronic stress, which may, in turn, exacerbate some types of psoriasis [17]. In clinical practice, HRQoL is considered to be an aid for clinical decision making, monitoring the therapeutic process, communicating with the patient, and evaluating treatment outcome [18].

Adjustment to chronic disease is a combined process, which is determined by the characteristics of the diseases (clinical presentation, lesion severity, duration, prognosis),

Address for correspondence: Alicja Ograczyk, Department of Psychodermatology, Medical University of Lodz, 251 Pomorska St, 92-213 Lodz, Poland, phone: +48 502099 388, e-mail: alicja-ograczyk@o2.pl

Received: 19.11.2012, accepted: 10.02.2013. 
external factors (e.g. social support, life situation, attitude of the environment) and internal factors (e.g. temperament, personality, personal resources such as optimism, coping with stress strategies). The above-mentioned factors influence each other by creating different networks [1922]. As Janković et al. [23] said knowledge of mind-bodyenvironment interactions can help to improve patients' skin conditions and, ultimately, their quality of life.

\section{Aim}

The aim of this study was to examine the relationship between HRQoL in psoriatics and selected demographic, medical and psychological (dispositional optimism) variables. An attempt was also made to determine predictors of $\mathrm{HRQOL}$ in the examined group.

\section{Material and methods}

The study consisted of 138 patients with the diagnosis of psoriasis vulgaris. Most respondents (91.9\%) presented

Table 1. Characteristics of patients with psoriasis

\begin{tabular}{|c|c|c|c|c|}
\hline Examined variables & \multicolumn{2}{|c|}{$N$} & \multicolumn{2}{|c|}{ Percentage } \\
\hline \multicolumn{5}{|l|}{ Sex } \\
\hline Men & \multicolumn{2}{|c|}{80} & \multicolumn{2}{|c|}{58} \\
\hline Women & \multicolumn{2}{|c|}{56} & \multicolumn{2}{|c|}{42} \\
\hline \multicolumn{5}{|l|}{ Educational level } \\
\hline Primary & \multicolumn{2}{|c|}{33} & \multicolumn{2}{|c|}{24.3} \\
\hline Vocational/secondary & \multicolumn{2}{|c|}{95} & \multicolumn{2}{|c|}{69.8} \\
\hline University degree & \multicolumn{2}{|c|}{8} & \multicolumn{2}{|c|}{5.9} \\
\hline \multicolumn{5}{|l|}{ Marital status } \\
\hline Single & \multicolumn{2}{|c|}{51} & \multicolumn{2}{|c|}{37.5} \\
\hline Married & \multicolumn{2}{|c|}{62} & \multicolumn{2}{|c|}{45.6} \\
\hline Divorced & \multicolumn{2}{|c|}{21} & \multicolumn{2}{|c|}{15.4} \\
\hline Widowed & \multicolumn{2}{|c|}{2} & \multicolumn{2}{|c|}{1.5} \\
\hline \multicolumn{5}{|l|}{ Psoriasis family history } \\
\hline Yes & \multicolumn{2}{|c|}{64} & \multicolumn{2}{|c|}{47.1} \\
\hline No & \multicolumn{2}{|c|}{72} & \multicolumn{2}{|c|}{52.9} \\
\hline \multicolumn{5}{|c|}{ Psoriasis on exposed parts of the body } \\
\hline Yes & \multicolumn{2}{|c|}{125} & \multicolumn{2}{|c|}{91.9} \\
\hline \multirow[t]{2}{*}{ No } & \multicolumn{2}{|c|}{11} & \multicolumn{2}{|c|}{8.1} \\
\hline & $M$ & SD & Min & Max \\
\hline Psoriasis severity (PASI) & 13.7 & 7.8 & 1.8 & 39.8 \\
\hline Disease duration [years] & 15.3 & 11.9 & 1.0 & 50.0 \\
\hline Age & 40.1 & 13.7 & 18.0 & 70.0 \\
\hline
\end{tabular}

psoriasis on exposed parts of the body, i.e. the face, neck, head and hands. Mean age was 40.1 years (min. 18 years, max. 70 years, $S D=13.7$ ), mean disease duration, calculated from the moment of the diagnosis to the study day was 15.3 years (min. 6 months, max. 50 years, SD =11.9). The severity of psoriasis was measured by the Psoriasis Area and Severity Index (PASI) with an average of 13.7 (min. 1.8, max. 39.8; $\mathrm{SD}=7.8$ ). Only patients with psoriasis vulgaris and without any other serious chronic diseases took part in the study, which was approved by the Medical University of Lodz Bioethics Committee. The patients gave their informed consent to participate in the study. Detailed characteristics of the participants are presented in Table 1.

The study used following methods:

- SKINDEX-29 - is a three-dimensional, dermatologyspecific HRQoL questionnaire tool [23, 24]. It is composed of 29 items assessing disease symptoms, emotions and social functioning. The questions refer to the previous 4-week period. The scores are given on a 5 -point scale ranging from "never" to "all the time". Higher scores indicate lower levels of quality of life.

- Life Orientation Test - LOT-R (Scheier, Carver, Bridges, as adapted to Polish conditions by Poprawa, Juczyński [25]) to measure dispositional optimism (defined as a generalized expectation of positive life events). Life Orientation Test contains 10 items, of which six constitute the diagnostic value. A patient fills the scale after reading the instruction, explaining the principles of assessment. Answers are marked on a 5-point scale. The overall result is the sum of the evaluation of six statements, including three positive and three negative ones. The distribution of the results after changing assessments covers the range from 0 to 24 points. The higher the scores the higher the level of optimism. Polish adaptation of LOT-R has good psychometric properties.

- PASI (Psoriasis Area and Severity Index) - scale to measure the severity of lesions in psoriasis [26] and allow its objective assessment.

Information was also collected on the basis of sociodemographic data of the examined group.

\section{Statistical analysis}

Statistical analysis was performed using the SPSS package for Windows (IBM SPSS Statistics 19). The distribution of the obtained results did not differ significantly from normal distribution. The Student's t-test $(t)$, Pearson correlation and multiple regression analysis were employed. A $p$ value below 0.05 was considered statistically significant.

\section{Results}

The first step of our analysis was to estimate the level of HRQoL and optimism experienced by men and women. But it turned out that gender does not differentiate respondents in terms of HRQoL and optimism (Table 2). 
Table 2. Mean scores and standard deviations of health-related quality of life and optimism in relation to gender

\begin{tabular}{lccccccc}
\hline Variables & \multicolumn{2}{c}{$\begin{array}{c}\text { Men } \\
(n=80)\end{array}$} & \multicolumn{2}{c}{$\begin{array}{c}\text { Women } \\
(n=56)\end{array}$} & & Value of $t$ & Value of $p$ \\
\cline { 2 - 6 } & $M$ & SD & M & SD & & \\
\hline Symptoms & 19.25 & 5.96 & 19.94 & 5.32 & -0.69 & 0.37 \\
\hline Emotions & 31.05 & 9.76 & 31.15 & 9.49 & -0.05 & 0.83 \\
\hline Functioning & 34.91 & 11.42 & 34.67 & 11.31 & 0.11 & 0.95 \\
\hline Overall & 85.31 & 23.24 & 85.67 & 24.22 & -0.08 & 0.75 \\
\hline Optimism & 25.83 & 5.79 & 24.94 & 6.44 & 0.84 & 0.37 \\
\hline
\end{tabular}

$M-$ mean, $S D$ - standard deviation, $t$-Student t-test, $p$ - significance level

Table 3. Correlation coefficient (Pearson's $r$ ) between health-related quality of life and analyzed variables

\begin{tabular}{lcccc}
\hline Variables & Symptoms & Emotions & Functioning & Overall \\
\hline Optimism & $-0.27^{*}$ & $-0.32^{*}$ & $-0.35^{*}$ & $-0.36^{*}$ \\
\hline Psoriasis severity (PASI) & $0.30^{*}$ & 0.15 & $0.39^{\star}$ & $0.32^{*}$ \\
\hline Disease duration & $0.27^{*}$ & -0.01 & 0.10 & 0.11 \\
\hline Age & $0.34^{*}$ & $0.22^{*}$ & $0.29^{*}$ & $0.31^{*}$ \\
\hline${ }^{*} p<0.05 ;$ PASI - Psoriasis Area and Severity Index & & &
\end{tabular}

Table 4. Determinants of overall health-related quality of life

\begin{tabular}{lcccccc}
\hline Variables & Value of $\boldsymbol{\beta}$ & $\boldsymbol{\beta}$ error & Value of B & B error & Value of $t$ & Value of $p$ \\
\hline Optimism & -0.35 & 0.07 & -1.40 & 0.29 & -4.74 & $<0.001$ \\
\hline Age & 0.29 & 0.08 & 0.50 & 0.15 & 3.35 & $<0.001$ \\
\hline Disease duration & -0.17 & 0.08 & -0.35 & 0.17 & -2.07 & 0.04 \\
\hline Psoriasis severity (PASI) & 0.25 & 0.07 & 0.77 & 0.22 & 3.35 & 0.001 \\
\hline Absolute term & & & 95.93 & 10.91 & 8.79 & $<0.001$ \\
\hline
\end{tabular}

$R=0.53, R^{2}=0.28, F=(4.131)=13.112, p<0.000 ; R$-regression analysis coefficient, $R^{2}-$ multiple regression analysis coefficient, $\beta-\beta$ coefficient, $B-B$ factor, $B$ error-standard error of $B, T$ - t-test value, $p$-statistical significance, $F$-value of F test, PASI - Psoriasis Area and Severity Index

In order to determine the relationship between the studied variables, Pearson's $r$-ratio was used (Table 3). In psoriatic patients almost all of analyzed variables correlate with HRQoL. Optimism correlates negatively with three SKINDEX domains and the overall score. It means that the stronger optimism the better evaluation of HRQoL (disease symptoms, emotions and social functioning). These relations are of moderate strength. Psoriasis severity correlates positively with reported symptoms, functioning and the overall score - the more severe skin condition the worse HRQoL. Disease duration correlates positively only with symptoms the longer duration the worse psoriasis symptoms reported by the patients. Age correlates positively with all domains and the overall score.

The last stage of our analysis was to search for determinants of HRQOL. In this regard, stepwise multiple regression model was used (Table 4). In patients with psoriasis, all examined variables explain the variability in results
(28\%) for overall HRQoL. Optimism explains the highest percentage of the variability $(\beta=-0.35)$.

\section{Discussion}

Psoriasis significantly affects daily functioning, significantly reduces the quality of life and is the cause of many psychosocial problems [27-31]. Studies emphasize that dermatological patients define skin diseases as particularly burdensome, being a source of stress and anxiety, significantly reducing the quality of life [30, 32].

Our study demonstrated that gender did not differentiate patients with psoriasis in terms of HRQOL and optimism - both men and women declared comparable levels of the psychological variables. No relation between sex and quality of life was also confirmed by de Korte et al. [27]. It should be noted that there are studies showing that psoriasis is associated with significantly worse assessment of 
functioning in women [24, 33-35]. As for study limitations our group of psoriatic patients differed in number between men and women.

Furthermore, our study demonstrated that almost all of analyzed variables correlated with HRQoL. It means that stronger optimism is connected with better subjective evaluation of quality of life (better subjective evaluation of lesion severity, lower intensity of negative emotions, fewer difficulties with everyday functioning and better relations with other people). Optimism can influence one's mood as so-called emotional background and being in a good mood favors development and maintenance of satisfaction and influences quality of life leading to its subjective increase [36, 37].

Psoriasis severity correlates positively with symptoms, functioning and the overall score. It seems to be understandable - the more severe skin condition the worse quality of life (like assessment of lesion severity and experiencing problems with social functioning). In the literature data, disease severity appeared to be associated with quality of life. Most of authors demonstrate such correlation [27, 35, 38-41], however the association was generally weak. Also, we found only one study without the mentioned relationship [42].

Moreover, literature data point out to the location of the lesions on visible parts of the body as having a strong influence on HRQoL [35, 38-41]. But, it is worth pointing out that the vast majority of our patients (91.9\%) presented visible skin lesions. And regarding study limitations the studied group comprised only hospitalized patients who generally presented more severe disease than out-patients do.

Furthermore, disease duration correlates positively only with symptoms - the longer duration the worse psoriasis symptoms reported. Also age correlates positively with all domains and the overall score (older people experience more problems with physical, emotional and social functioning). On the contrary, some studies showed [43] that the older patients present greater negative emotion control. With age control of negative emotions seems to be more intense. On the contrary to the above study, our results suggested that adjusting to psoriasis later in life may be more difficult than at an earlier age, when a patient is young and has a lot of time to learn to deal with negative emotions.

Based on the above data, one can easily conclude that $\mathrm{HRQOL}$ is a complicated issue. It requires further interdisciplinary research investigating numerous medical and psychological aspects of psoriasis. It is worth taking into account that one's illness perception and dynamics of adaptation to psoriasis depend on the phase of the disease and experiencing both positive and negative emotions [44]. Nonetheless, the results of our study may form the basis for psychological intervention employment in psoriatic patients. They point out to usefulness of cognitive-behavioral techniques [45] in order to change psoriatic patients' beliefs and expectations (like dispositional optimism defined as generalized expectation of positive life events).
Changing beliefs and expectations, regardless of the disease severity and other medical variables, may exert a positive impact on the patients' HRQoL.

\section{Acknowledgments}

This study was supported by the National Research Grant nr NN 404029438.

\section{References}

1. Mazzotti E, Mastroeni S, Lindau J, et al. Psychological distress and coping strategies in patients attending a dermatology outpatient clinic. J Eur Acad Dermatol Venereol 2012; 26: 746-54

2. Steuden S, Janowski K. Psychodermatological diseases [Polish]. Przegl Dermatol 2002; 89: 175-83.

3. Zalewska-Janowska A. Psychodermatology in allergology [Polish]. Alergia Astma Immunologia 2010; 15: 109-17.

4. Pastuszka M, Tyc-Zdrojewska E, Uczniak S, et al. Current concepts of aetiopathogenesis of psoriasis [Polish]. Postep Derm Alergol 2011; 26 (Suppl. 3): 117-31.

5. Ingram JT. The significance and management of psoriasis. BMJ 1954; 24: 823-8.

6. Susskind M, McGuire RJ. The emotional factor in psoriasis. Scot Med J 1959; 4: 503-7.

7. O'Leary CJ, Creamer D, Higgins E, Weinman J. Perceived stress, stress attributions and psychological distress in psoriasis. J Psychosom Res 2004; 57: 465-71.

8. Rieder E, Tausk F. Psoriasis, a model of dermatologic psychosomatic disease: psychiatric implications and treatments. Int J Dermatol 2012; 51: 12-26.

9. Palijan TZ, Kovacević D, Koić E, et al. The impact of psoriasis on the quality of life and psychological characteristics of persons suffering from psoriasis. Coll Antropol 2011; 35 (Suppl. 2): 81-5.

10. Sampogna F, Tabolli S, Abeni D. Living with psoriasis: prevalence of shame, anger, worry, and problems in daily activities and social life. Acta Derm Venerol 2012; 92: 299-303.

11. Kurd SK, Troxel AB, Crits-Christoph P, Gelfand JM. The risk of depression, anxiety, and suicidality in patients with psoriasis: a population-based cohort study. Arch Dermatol 2010; 146: 891-5.

12. Ograczyk A, Malec J, Miniszewska J, et al. Psychological aspects of atopic dermatitis and contact dermatitis: stress coping strategies and stigmatization. Postep Derm Alergol 2012; 29: 14-8

13. Zalewska A, Miniszewska J, Woźniacka A, et al. Disease coping and quality of life in psoriasis vulgaris patients [Polish]. Przegl Dermatol 2003; 90: 267-72.

14. Zalewska A, Miniszewska J, Chodkiewicz J, et al. Acceptance of chronic illness in psoriasis vulgaris patients. JEADV 2007; 21: $235-242$

15. Marcia A, Testa MP, Simonson DC. Assessment of qualityof-life outcomes. N Engl J Med 1996; 334: 835-40.

16. Żukiewicz-Sobczak W, Krasowska E, Zwoliński J, et al. Allergic diseases - current state of knowledge. Postep Derm Alergol 2012; 29: 451-5.

17. Janković S, Raznatović M, Marinković J, et al. Relevance of psychosomatic factors in psoriasis: a case-control study. Acta Derm Venerol 2009; 89: 364-8.

18. Guyatt GH, Osoba D, Wu AW, et al. Methods to explain the clinical significance of health status measures. Mayo Clin Proc 2002; 77: 371-83. 
19. Heszen I, Sęk H. Health Psychology [Polish]. PWN, Warsaw 2007.

20. Steuden S. The psychological problem of health and disease. In: Oleś P, Steuden S, Toczydłowski J (eds.). How I see the world less [Polish]. TN KUL, Lublin 2002.

21. Baelum J, Larsen P, Doekes G, Sigsgaard T. Health effects of selected microbiological control agents. A 3-year follow-up study. Ann Agric Environ Med 2012; 19: 631-6.

22. Jenerowicz D, Silny W, Dańczak-Pazdrowska A, et al. Environmental factors and allergic diseases. Ann Agric Environ Med 2012; 19: 475-81.

23. Chren MM, Lasek RJ, Quinn LM, et al. Skindex, a quality-oflife measure for patients with skin diseases: reliability, validity and responsiveness. J Invest Dermatol 1996; 107: 707-13.

24. Steuden S, Janowski K. The employment of Skindex questionnaire to measure quality of life in patients with psoriasis [Polish]. Przegl Dermatol 2001; 88: 41-8.

25. Juczyński Z. Evaluation tools in health promotion and psychology [Polish]. PTP, Warsaw 2001.

26. Fredriksson T, Petersson U. Severe psoriasis - oral therapy with a new method. Dermatologica 1978; 157: 238-44.

27. De Korte J, Sprangers MAG, Mombers FMC, et al. Quality of life in patients with psoriasis: a systematic literature review. J Invest Dermatol Symposium Proceedings 2004; 2: 140-7.

28. Dubertret L, Mrowietz U, Ranki A, et al. European patient perspectives on the impact of psoriasis: the EUROPSO patient membership survey. Br J Dermatol 2006; 4: 729-36.

29. Janowski K. Quality of life associated with health and its measurement. In: Steuden S, Ledwoch M (eds.). The selected problems from clinical psychology and psychology of personality. Sick human being problems [Polish]. TN KUL, Lublin 2005.

30. Janowski K. Quality of life problems in dermatological diseases. In: Quality of life in disease [Polish]. Steuden S, Okła W (eds.). KUL, Lublin 2006.

31. Żelazny I, Nowicki R, Majkowicz M, et al. Quality of life in skin diseases [Polish]. Przegl Lek 2004; 9: 60-5.

32. Kępska A, Haftek M, Nosbaum A, et al. Psychological stress and transepidermal water loss in atopic dermatitis: preliminary results. Postep Derm Alergol 2012; 4: 263-6.

33. Dalgard F, Svensson A, Holm J, et al. Self-reported skin morbidity among adults: associations with quality of life and general health in a Norwegian survey. J Invest Dermatol 2004; 9: 120-5.

34. Uttjek M, Dufaker M, Nygren L, et al. Determinants of quality of life in a psoriasis population in Northern Sweden. Acta Derm Venerol 2004; 84: 37-43.

35. Zachariae R, Zachariae H, Ibsen HHW, et al. Psychological symptoms and quality of life of dermatology outpatients and hospitalized dermatology patients. Acta Derm Venerol 2004; 84: 205-12.

36. Stach R. Optimism evaluation questionnaire [Polish]. Publishing of Jagiellonian University, Krakow 2001.

37. Stach R. Optimism. Study on optimism as a adaptation mechanism [Polish]. Publishing of Jagiellonian University, Krakow 2006.

38. Rapp SR, Cottrell CA, Leary MR. Social coping strategies associated with quality of life decrements among psoriasis patients. Br J Dermatol 2001; 145: 610-6.

39. Vardy D, Besser A, Amir M, et al. Experiences of stigmatization play a role in mediating the impact of disease severity on quality of life in psoriasis patients. Br J Dermatol 2002; 147: 736-42.
40. Heydendael VMR, de Borgie CAJ, Spuls PI, et al. The burden of psoriasis is not determined by disease severity only. $J$ Invest Dermatol Symposium Proceedings 2004; 9: 131-5.

41. Al-Mazeedi K, El-Shazly M, Al-Ajmi HS. Impact of psoriasis on quality of life in Kuwait. Int I Dermatol 2006; 45: 418-32.

42. Fortune DG, Main CJ, O'Sullivan TM, et al. Quality of life in patients with psoriasis: the contribution of clinical variables and psoriasis-specific stress. Br J Dermatol 1997; 137: 755-60.

43. Kossakowska MM, Cieślińska C, Jaszewska JU, et al. Control of negative emotions and its implication for illness perception among psoriasis and vitiligo patients. JEADV 2010; 24: 429-33.

44. Heszen I. Health problems and coping with them-from denial to positive emotions. In: Health in the human life cycle [Polish]. Ogińska-Bulik N, Miniszewska J (eds). Publishing of University of Lodz, Lodz 2012.

45. Chodkiewicz J, Miniszewska J. The present application and the progress of cognitive-behavioral therapy. [Polish]. Psychiatr Pol 2006; 2: 279-90. 